extreme uncreativity - the blind repetitiveness of instinctive behaviour shown by the wasp Sphex. Typically, he gives this behaviour a name: sphexishness. Its opposite, mental flexibility, he calls antisphexishness; and to illustrate the notion he positions various machine, animal and human behaviours along a continuum connecting these extremes. The essence of antisphexishness, says Hofstadter, is the ability to break out of loops and ruts of all

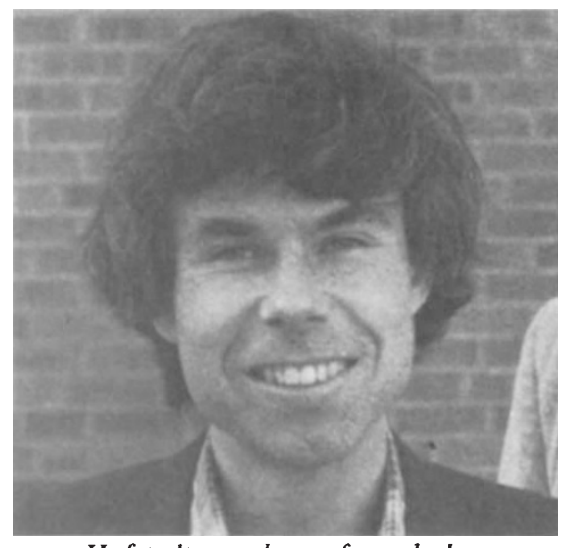

Hofstadter - love of word-play.

kinds. He has a word for this, too: "jootsing" (jumping out of the system). It depends, he argues, on watching what you're doing, so as to break up any routine which is getting repetitive. This leads into his favourite topic of self-watching and self-referencing systems, recursive theorems and computer-routines, and the use of recursiveness in "creative" computer programs. He ultimately concludes that some sort of Gödel theorem forbids any exhaustive formalization of creative ability. Any conceivable creative genius or artificially intelligent program must ultimately remain a prisoner of its own style - just like the humble Sphex.

In the postscript to this Thema, Hofstadter throws out some intriguing remarks about the subtleties of "style" (What makes a tune catchy? Why do tradenames such as "Day-glo" and "Turbomatic" now seem vaguely dated?), and comments on a new rival artificialintelligence strategy inspired not by recursion but by the ideas of statistical mechanics. The reader is directed to related discussions in other Themas.

Hofstadter is no mere armchair theorist. He constantly supports his ideas by appeals to practical experience or to intriguing psychological experiments. Expounding the Turing test for computer intelligence (can you distinguish the computer from a human being by its responses to questions?), he presents a transcript of an actual Turing test, with a delightful surprise ending. His discussion of the "Prisoner's Dilemma" paradox, a sort of mathematical microcosm of the tension between competition and cooperation, is enlivened by accounts of several experimental studies. Two of them were tests caried out by Hofstadter himself on human subjects, the other two were tournaments between computer pro- grams. The tournaments marvellously illuminate the biological concept of the "evolutionarily stable strategy" - the optimum behavioural strategy towards which a group of competing organisms will evolve over the generations. This is used to suggest how socially cooperative creatures could have evolved from a primitive population of warring egotists.

Hofstadter's style of writing has its own pleasures and pleasantries. He loves playing with words; puns, anagrams and literary jokes abound. This almost dangerous infatuation with word-play at times works against him. Three whole chapters are devoted to self-referencing sentences, a self-indulgence quite unjustified by the limited conclusions reached. Another chapter presents numerous examples of literary nonsense, again without any moral that I can see. Set against the commentaries by (for example) Aldous Huxley, George Orwell and John Updike on nonsense-verse considered as a penetrating subversion of the stifling world of convention, this is very thin gruel.

The most serious lapses, though, are political. Hofstadter declares himself a natural activist, easily "fired up" by various good causes. The ones he espouses here, those of nuclear disarmament and feminism, are badly served by his simplistic enthusiasm. His anti-nuclear Thema is a sadly flat and contrived parable, arguing that if enough people devote enough time to denouncing the arms-race, it will go away. Once world leaders realize the complete symmetry of the U.S./S.U. confrontation (there's that word-play again) all will surely be well. His feminist Themas point out that in normal grammatical English usage, "he" can include "she" and so on. He seeks to make this a matter for resentment among women, and guilt in men, by means of an extraordinary attempted mapping from a region of very high guiltdensity, that of race relations. Orwell, in his celebrated essay "Notes on Nationalism", remarks that the political bigot's great sensitivity to specific words and phrases probably has overtones of word-magic - the belief that the world can be changed by proper incantation. Despite his fascination with words, Hofstadter is too rational a soul to be a bigot. $\mathrm{He}$ admits that he may be over-acting. Certainly all previous attempts to change society by word-manipulation have merely enriched the language's glittering treasure-house of euphemisms and polite evasions.

But this is to carp. Most of Hofstadter's Themas are concerned with his areas of special knowledge and insight, and sparkle with linguistic fun, provocative insights and intellectual challenges. This random walk through his intellectual "home territory" is highly recommended.

David E.H. Jones is a guest staff member of the Physical Chemistry Department, University of Newcastle upon Tyne, and a science consultant to industry and the media.

\section{Life with a lighter touch}

\author{
Martin Gardner
}

"Surely You're Joking, Mr. Feynman!": Adventures of a Curious Character.

By Richard P. Feynman with Ralph

Leighton.

W.W. Norton: 1985. Pp.350. \$15.95. To be published in Britain later this year by $W . W$. Norton.

"THE stories Feynman tells about himself would make a book", an interviewer wrote in 1963. Here, 22 years later, is that book. It is not an autobiography. You will learn nothing from it about the work on quantum mechanics that earned Richard Feynman a Nobel prize in 1965 . What you will learn is a great deal about the flamboyant personality of a great theoretical physicist: his amazing range of interests, his unusual hobbies, his enthusiasms and animadversions, his dislike of pompous fools, his unpredictable behaviour and, above all, his fondness for outrageous comedy.

Feynman's famous three-volume Lectures on Physics, and his marvellous little book The Character of Physical Law, were based on taped lectures. Surely You're Joking, Mr. Feynman! is a taping of Feynman's uninhibited conversations over the years with his friend Ralph Leighton. "That one person could have so many wonderfully crazy things happen to him in one lifetime is sometimes hard to believe", Leighton writes in his preface.

The reason they happened is that Feynman has a knack of creating his own adventures. When, for instance, he was a young man at Los Alamos, working on the top secret bomb, he discovered a hole in the perimeter fence. Anyone else would have reported this to the authorities and that would have been the end of it, but Feynman is incapable of passing up a chance for a lark. Out of the main gate he goes, back through the hole, then out again. He keeps this up until the sergeant at the gate suddenly realizes that some strange character is always going out but never coming in.

Feynman's expert ability to pick locks followed naturally from his lifelong passion for puzzles. To demonstrate how loose security was at Los Alamos, he would secretly open the safes of top scientists, leaving little notes that said such things as "I borrowed document LA4312 - Feynman the safecracker". But such idiosyncracies were not appreciated by everyone, least of all the military. When three psychiatrists tried to test Feynman for Army service they quickly found themselves being tested. "How much do you value life?", one of them asked. "Sixty-four", Feynman answered. The Army's final verdict: mentally deficient. (The chapter on this banter, headed 
"Uncle Sam Doesn't Want You!", is one of the book's funniest.)

My favourite anecdote, however - it's vintage Feynman - concerns a joke his friends once tried to play on him. In Japan Feynman had learned some Japanese, and in Portugal he gave lectures in Portuguese. At a party someone thought it would be amusing to see how this "man of a thousand tongues" would react if a Caucasian lady, who grew up in China, greeted him in Chinese. "Ai, choong, ngong jia!" she said with a bow. Taken aback, Feynman swiftly decided the best thing to do was imitate the sounds she made. "Ah, ching, jong jien!" he replied, returning the bow. "Oh, my God!" the lady exclaimed. "I knew this would happen. I speak Mandarin and he speaks Cantonese!".

From childhood on, anything mysterious or puzzling instantly aroused Feynman's curiosity. Growing up in Long Island, New York, he taught himself how radios work and he became the neighbourhood's youngest radio repair man. He invented ingenious experiments with ants to work out how their brains were programmed. Intrigued by hypnotism, he allowed himself to be hypnotized. To experience out-of-body hallucinations, he floated in a sensory deprivation tank. Always, wherever he was or whatever he did, the wheeis in Feynman's brain never stopped whirring. Every experience posed new challenging questions. What goes on here? Why does this work? Can it be done better? The best example echoes Newton and the apple (no, that story isn't a myth). Feynman once watched someone toss a plate in the air and noticed that its wobble went around faster than the plate. It started a train of thought that eventually led to the Feynman diagrams for particle interactions and to the work that won the Nobel award.

The book swarms with delightful glimpses of the famous: Einstein, Bohr, Wheeler, Wigner, Oppenheimer, Teller, Pauli, Compton, Fermi, Gell-Mann and many others. (It is said that the California Institute of Technology, where Feynman has taught since 1950, hired Murray GellMann so Feynman would have someone to talk to.) And it was, apparently, a casual remark of one of them, John von Neumann, that gave Feynman a sense of political detachment that he claims has kept him happy ever since. You don't have to feel responsible, the great mathematician told him, for the state of the world. Not for its social and political insanities, perhaps, but trying to understand how nature works on her deepest level is a responsibility - perhaps pleasure is a better word for what Feynman feels - that he surely has not taken lightly.

Martin Gardner, formerly a staff writer for Scientific American, is a contributing editor of Discover. He is author of many books, the most recent of which is Order and Surprise (Oxford University Press, 1984).

\section{Global matters}

\section{David R. Rosseinsky}

The Cambridge Guide to the Material World.

By Rodney Cotterill.

Cambridge University Press: 1985.

Pp.352. £17.50, \$34.50.

"WE are living in a material world" is the burden of a current popular song, and this inviting tome comprehensively portrays its component materials. While - despite the title - not exactly instruction against table book, despite the large and colourful jacket) it possibly does have a message underlying its non-mathematical account of materials. Some are materials as in materials science, that is to say mainly solids (metals, polymers, ceramics and the like, together with the new organic superconductors and kindred exotica) but also included are nucleic acids, cells, living systems and their operation. More than a third of the book is devoted to biological materials, metabolism, nerve and brain operation and so on. Perhaps the philosophical drift of this mechanistic outline lies in the concluding sentence "The nature of the mind remains a mystery". And thereby may the title be nicely justified.

The level of exposition is a mature one, even though for example the concept of potential energy itself has to be established in terms of uphill and downhill travel. Description of nuclear and atomic structures leads on to the complexity of, for instance, excessive monasticism (nor yet a coffee-

the superconductivity mechanism. Experiment is included insofar as it aids the continuity of description. Lively historical exposition is often followed, and individuals are named at a pleasing narrative pace. And there are many fine illustrations, often in colour.

All is not quite perfect, however: we could do without the entropy death of the Universe (yet again), and on the atomic scale some aspects are just wrong rather than oversimplified. Thus $p$ orbitals are not appropriately represented, the hydrogen bond and electron affinity suffer in verbal compression, the invention of the $T$-jump rate measurement is wrongly ascribed and so on. It is a measure of the book's overall strength, however, that the description of materials, which is the author's métier, survives such shortfalls in the physics and chemistry at the beginning.

What will be the readership of such a book? Certainly established physical scientists will benefit (and perhaps feel smart at spotting the occasional slip). But all enquiring amateur or professional scientists and technologists of whatever origin or age should enjoy it, and possibly the eye-catching jacket will fulfil the role of the Venus fly-trap depicted there. The price is such as to encourage private investment, and who knows, even as a coffeetable book it could do good by stealth. In Britain the invaluable campaign for "Women into Science and Engineering" goes under the acronym WISE, and for a WISE education, no Material Girl (of the pop song) should be without a copy. $\square$

David R. Rosseinsky is Reader in Physical Chemistry at the University of Exeter.



Visual distraction - Maurits Escher's "Prentententoonstelling", reproduced from the chapter on crystal defects in The Cambridge Guide to the Material World. 